\title{
Action of aluminum on high voltage-dependent calcium current and its modulation by ginkgolide $B$
}

\author{
Lei CHEN, Chang-jin LIU ${ }^{1}$, Ming TANG, Ai LI, Xin-wu HU, Yi-mei DU, Jing-jing SHEN, Yong-li LU, Jurgen HESCHLER²
}

Department of Physiology, Tongji Medical College, Huazhong University of Science and Technology, Wuhan 430030, China $;^{2}$ Institute of Neurophysiology, University of Cologne, Cologne D-50931, Germany

\author{
Key words \\ hippocampus; aluminum; voltage-dependent \\ calcium channels; ginkgolide B; patch-clamp \\ technique \\ ${ }^{1}$ Correspondence to Prof Chang-jin LIU. \\ Phn 86-27-8369-1545. \\ Fax 86-27-8369-2608. \\ E-mail tjchangjinliu@hotmail.com \\ Received 2004-09-20 \\ Accepted 2004-12-09 \\ doi: $10.1111 / \mathrm{j} .1745-7254.2005 .00073 . x$
}

\begin{abstract}
Aim: To investigate the effect of aluminum (Al) on high voltage-dependent calcium current $\left(I_{\mathrm{HVA}}\right)$ and its modulation by ginkgolide B (Gin B). Methods: The whole-cell, patch-clamp technique was used to record $I_{\mathrm{HVA}}$ from acutely isolated hippocampal CA1 pyramydal neurons in rats. Results: Al $0.1 \mathrm{mmol} / \mathrm{L}$ (low concentration) reduced $I_{\mathrm{HVA}} ; \mathrm{Al} 0.75$ and $1.0 \mathrm{mmol} / \mathrm{L}$ (high concentrations) increased $I_{\mathrm{HVA}}$, and $\mathrm{Al}$ decreased and increased $I_{\mathrm{HVA}}$ at intermediate concentrations of 0.25 and $0.5 \mathrm{mmol} / \mathrm{L}$. The increase of $I_{\mathrm{HVA}}$ by Al $1.0 \mathrm{mmol} / \mathrm{L}$ was enhanced by the adenylyl cyclase (AC) agonist forskolin and was partly abolished by the cyclic adenosine monophosphate (cAMP)-dependent protein kinase A (PKA) antagonist $\mathrm{H}-89$, whereas the decrease observed with $\mathrm{Al} 0.1 \mathrm{mmol} / \mathrm{L}$ was neither reversed by forskolin nor affected by H-89. Gin B had no effect on $I_{\mathrm{HVA}}$ in normal neurons, but canceled the increase in $I_{\mathrm{HVA}}$ by $1.0 \mathrm{mmol} / \mathrm{L} \mathrm{Al}$. Conclusion: The results indicate that the mechanism of Al affecting $I_{\mathrm{HVA}}$ differs at different concentrations, and this may be attributed to its complex actions. Gin B could prevent neurons from injury by inhibiting calcium influx.
\end{abstract}

\section{Introduction}

The accumulation of aluminum (Al) within the body can result in many mental diseases. For example, $\mathrm{Al}$ is concentrated in the neurofibrillary tangles and senile plaques of patients with Alzheimer disease $(\mathrm{AD})^{[1]}$. Al can be attributed to several neurological disorders, such as dialysis syndrome and Guamanian amylotrophic lateral sclerosis-Parkinson's dementia $^{[2]}$. A number of studies have implicated that Al has no effect on long-term potentiation (LTP $)^{[3]}$. However, more and more studies have shown that Al can impair $\mathrm{LTP}^{[4]}$ and evoke potential in the hippocampus ${ }^{[5]}$. Studies have also shown that $\mathrm{Al}$ affects amino acid neurotransmitters in the hippocampus and enhances glutamate-mediated excitotoxicity, which may be one of the causes of its toxicity ${ }^{[6]}$. Reports about its mechanism involving ion channels are few and controversial ${ }^{[7-9]}$.

Extracts from leaves of Ginkgo biloba $(E G \mathrm{~b})$ and one of its constituents ginkgolide B have been demonstrated to protect cardiomyocytes and cultured neurons from the in- jury induced by hypoxia, ischemia, and the neurotoxicity induced by $A \beta^{[10-12]}$. However, it is not known whether the mechanism of this protection of neurons involves ion channels, such as voltage-dependent calcium channels (VDCC).

The present study investigated the actions of $\mathrm{Al}$ on $I_{\mathrm{HVA}}$ and its modulation by Gin B to examine the neurotoxic mechanisms of $\mathrm{Al}$ and the neuroprotective mechanisms of Gin B.

\section{Materials and methods}

Reagents Pronase E, forskolin, TEA-Cl, H-89, and HEPES were purchased from Sigma Chemical Company (St Louis, MO, USA). H-89 was dissolved in pipette solution and stored at $-20^{\circ} \mathrm{C}$. After the whole-cell configuration was constructed, H-89 was dialyzed into the cell through the pipette. Ginkgolide B (BN52021, purity 98.2\%) was from the Wuhan Institute of Botany, Chinese Academy of Sciences (Wuhan, China). $\mathrm{AlCl}_{3}$ was from Jinghua Chemical Company (Beijing, China). The remaining chemicals, unless otherwise 
stated, were all purchased from the Shanghai Chemical Reagent Plant (Shanghai, China).

Cell isolation Animals were provided by the experimental animal center of Tongji Medical College (Grade II, Certificate № $19-050)$. Hippocampal CA1 neurons were acutely isolated by enzymatic digestion and mechanical dispersion from 7 to 10 -d-old Wistar rats as described in a previous study ${ }^{[13]}$, with a few modifications. After the animals were killed, the hippocampi were removed and coronary slices were cut at a thickness of approximately $500 \mu \mathrm{m}$ in ice-cold oxygenated incubation solution within $30 \mathrm{~s}$. The slices were incubated in an external solution saturated with pure $\mathrm{O}_{2}$ at $32{ }^{\circ} \mathrm{C}$ for $1 \mathrm{~h}$, treated with Pronase E $6.0-7.0 \mathrm{kU} / \mathrm{L}$ for $25 \mathrm{~min}$ in the oxygenated external solution at $32{ }^{\circ} \mathrm{C}$. After digestion the slices were washed six times with external solution and incubated in the same solution saturated with pure $\mathrm{O}_{2}$ at room temperature. CA1 regions were dissected out and transferred into centrifuge tubes. Hippocampal neurons were dispersed by gentle pipetting using fine glass tubes. After 5 min, the cell suspension was transferred into the recording chamber with a glass coverslip filled with external solution. The cells were left for approximately $30 \mathrm{~min}$ before beginning the experiments.

Electrophysiology The cells were placed in a recording chamber mounted on the stage of an inverted microscope (Carl Zeiss, Germany) and superfused with extra cellular solution at room temperature $\left(21-22^{\circ} \mathrm{C}\right)$. Extracellular solution for recording $I_{\mathrm{HVA}}$ was composed of (mmol/L): $\mathrm{NaCl} 150, \mathrm{KCl}$ 5, $\mathrm{MgCl}_{2}$ 1.1, $\mathrm{CaCl}_{2}$ 2.5, HEPES 10, glucose 10, TTX 0.001, and the $\mathrm{pH}$ was adjusted to 7.4 with $\mathrm{NaOH}$. Extracellular application of drugs was carried out by perfusing cells with extracellular solution containing the drugs.

Whole-cell patch experiments were carried out using an Axopatch 200A amplifier (Axon Instruments, Foster City, CA, USA) driven by ISO2 software (MFK, Frankfurt, Germany). In the voltage-clamp experiments, the cells were stepped from $-80 \mathrm{mV}(50 \mathrm{~ms})$ to $-40 \mathrm{mV}(200 \mathrm{~ms})$, and then depolarized to 0 $\mathrm{mV}(200 \mathrm{~ms})$ after briefly hyperpolarizing the membrane potential for $10 \mathrm{~ms}$ to $-45 \mathrm{mV}$. The $I_{\mathrm{HVA}}$ was activated by the second depolarization. The protocol was applied every $5 \mathrm{~s}$. For analysis of the current-voltage $(I-V)$ relationship, voltage steps $(200 \mathrm{~ms})$ were used to depolarize from $-40 \mathrm{mV}$ to $+40 \mathrm{mV}$ in $10 \mathrm{mV}$ increments. Glass pipettes were used with a resistance of about 3-5 $\mathrm{M} \Omega$ when filled with a pipette solution composed of (mmol/L): $\mathrm{CsCl} 140, \mathrm{MgCl}_{2} 2$, $\mathrm{Mg}$-ATP 4, TEA-Cl 2, HEPES 10, egtazic acid 11, and the $\mathrm{pH}$ was adjusted to 7.2 with $\mathrm{CsOH}$.

Data were acquired at a sampling rate of $10 \mathrm{kHz}$, filtered at $2 \mathrm{kHz}$, stored on hard disk and analyzed off-line using the
ISO2 analysis software package (MFK, Frankfurt, Germany).

Data analysis The amplitude of $I_{\mathrm{HVA}}$ was calculated as the difference between the instantaneous current at the beginning of the experiment and the maximum activating current. Currents were normalized to membrane capacitance to calculate current densities $\left(\mathrm{pA} \cdot \mathrm{pF}^{-1}\right)$. Cell membrane capacitance (Cm) was determined online using the ISO2 software program. The activation rate constant and inactivation rate constant were obtained using the ISO2 analysis software. Graphical and statistical data analyses were carried out using Sigmaplot 2001 (SPSS, Chicago, IL, USA) and Origin 6.0 (Microcal Software, Inc, Northampton, MA01060, USA). Data were presented as mean \pm SEM where appropriate. Statistical analysis were carried out using Student's paired and unpaired $t$ tests and values of $P<0.05$ were considered statistically significant.

\section{Results}

Action of $\mathrm{Al}$ on $\boldsymbol{I}_{\mathrm{HVA}}$ Bath application of $\mathrm{AlCl}_{3} 0.01 \mathrm{mmol} / \mathrm{L}$ had no effect on $I_{\mathrm{HVA}}$. The current densities before and after $\mathrm{AlCl}_{3}$ application were $18.5 \pm 2.4 \mathrm{pA} \cdot \mathrm{pF}^{-1}$ and $18.5 \pm 2.2$ $\mathrm{pA} \cdot \mathrm{pF}^{-1}$, respectively $(n=11, P>0.05)$ (Figure $\left.1 \mathrm{~A}\right)$.

Bath application of $\mathrm{AlCl}_{3} 0.1 \mathrm{mmol} / \mathrm{L}$ caused a reduction in $I_{\mathrm{HVA}}$ from $17.7 \pm 1.6 \mathrm{pA} \cdot \mathrm{pF}^{-1}$ to $12.7 \pm 1.4 \mathrm{pA} \cdot \mathrm{pF}^{-1}(n=27, P<$ 0.01 ), that is, a reduction of $30.5 \% \pm 4.1 \%$. The reduction of $I_{\mathrm{HVA}}$ by $\mathrm{AlCl}_{3}$ did not recover after the $\mathrm{AlCl}_{3}$ was washed out (Figure 1B).

$\mathrm{AlCl}_{3} 0.25 \mathrm{mmol} / \mathrm{L}$ caused a reduction in $I_{\mathrm{HVA}}$ in $80 \%(8 / 15)$ of the neurons, and an increase in $20 \%(4 / 15)$ of the neurons. $\mathrm{AlCl}_{3} 0.50 \mathrm{mmol} / \mathrm{L}$ caused a reduction in $I_{\mathrm{HVA}}$ in $50 \%(7 / 14)$ of the neurons, and an increase in $I_{\mathrm{HVA}}$ in $50 \%(7 / 14)$ of the neurons. In contrast, $\mathrm{AlCl}_{3} 0.75 \mathrm{mmol} / \mathrm{L}$ increased $I_{\mathrm{HVA}}$ by $30.8 \% \pm 5.2 \%(n=15, P<0.01)$ in all neurons tested (from $17.8 \pm$ $1.8 \mathrm{pA} \cdot \mathrm{pF}^{-1}$ to $\left.23.0 \pm 2.5 \mathrm{pA} \cdot \mathrm{pF}^{-1}\right) . \mathrm{AlCl}_{3} 1.0 \mathrm{mmol} / \mathrm{L}$ increased


$(n=21, P<0.01) . I_{\mathrm{HVA}}$ increased by $\mathrm{AlCl}_{3}$ was irreversible after $\mathrm{AlCl}_{3}$ was washed out (Figure 1C).

At both low and high concentrations, $\mathrm{AlCl}_{3}$ inhibited or increased the maximum amplitude of $I_{\mathrm{HVA}}$, but had no effect on the activation threshold potential of $I_{\mathrm{HVA}}$ in the $I-V$ relationship (Figure 2A, B). The $G-V$ curve was unaffected by $\mathrm{AlCl}_{3} 0.1 \mathrm{mmol} / \mathrm{L}(n=5, P>0.05)$ or $\mathrm{AlCl}_{3} 1.0 \mathrm{mmol} / \mathrm{L}(n=5$, $P>0.05$ ) (control: $V_{0.5}=-12.8 \mathrm{mV} \pm 4.4 \mathrm{mV}, k=5.5 \pm 3.8 ; \mathrm{AlCl}_{3} 0.1$ $\mathrm{mmol} / \mathrm{L}: V_{0.5}=-12.0 \mathrm{mV} \pm 4.5 \mathrm{mV}, k=5.0 \pm 4.0 ; \mathrm{AlCl}_{3} 1.0 \mathrm{mmol} / \mathrm{L}$ : $V_{0.5}=-13.6 \mathrm{mV} \pm 5.3 \mathrm{mV}, k=5.2 \pm 4.4$ ) (Figure $2 \mathrm{C}$ ). In addition, $\mathrm{AlCl} 3$ had no effect on the activation rate constants at concentrations of $0.1 \mathrm{mmol} / \mathrm{L}(n=8, P>0.05)$ or $1.0 \mathrm{mmol} / \mathrm{L}(n=9$, $P>0.05)$. 
A
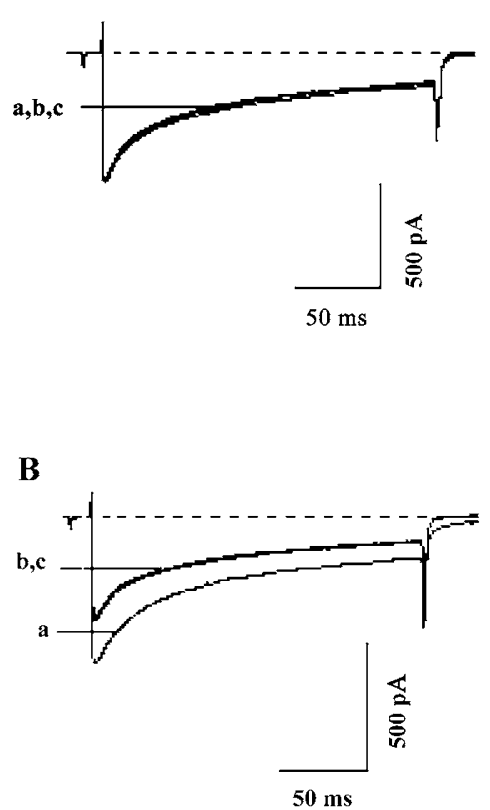

C



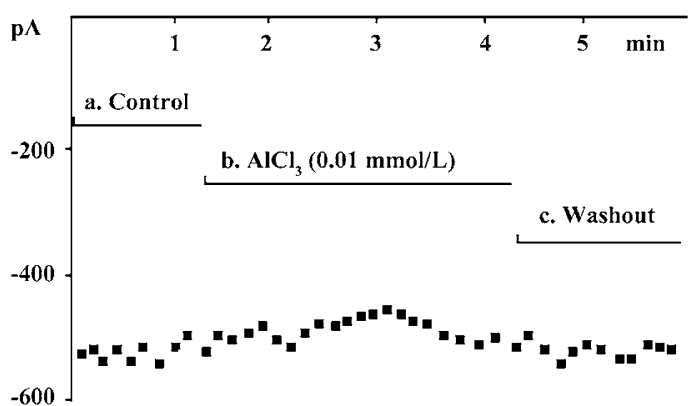
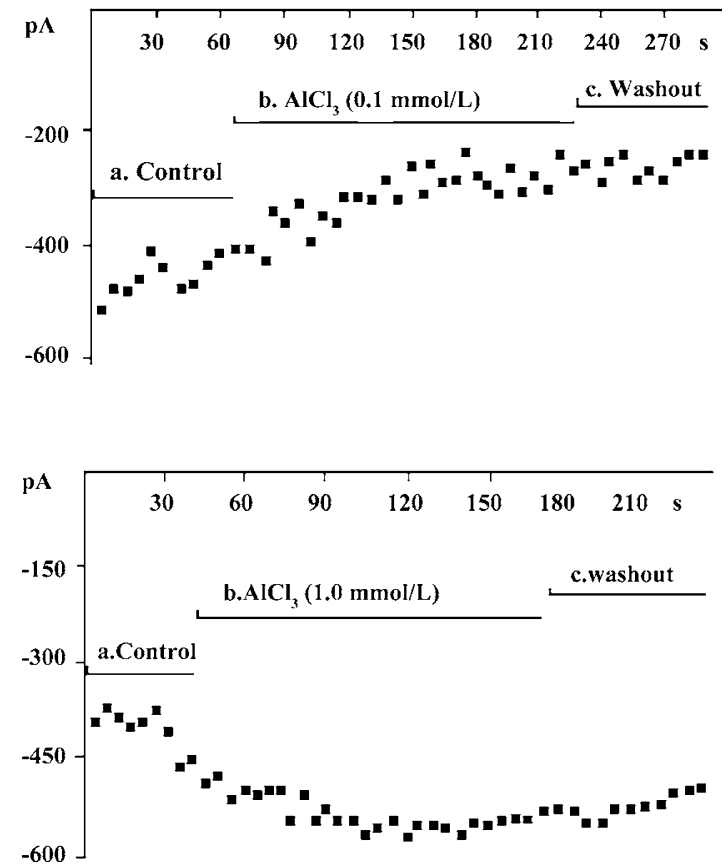

Figure 1. Effect of $\mathrm{AlCl}_{3}$ on $I_{\mathrm{HVA}}$ at concentrations of $0.01,0.1$ and $1.0 \mathrm{mmol} / \mathrm{L}$ (A, B, C, respectively). $I_{\mathrm{HVA}}$ current was recorded at different concentrations of $\mathrm{AlCl}_{3}$ (left). (a) Before the application of $\mathrm{AlCl}_{3}$; (b) Application of $\mathrm{AlCl}_{3}$; (c) washout. The time course of the experiment corresponding to left-hand panels (right).

To gain a better understanding of the action of $\mathrm{Al}$ on $I_{\mathrm{HVA}}$, we explored its action on the steady-state inactivation curve of $I_{\mathrm{HVA}} . \mathrm{AlCl}_{3}$ shifted the curve to a depolarizing voltage at $1.0 \mathrm{mmol} / \mathrm{L}(n=5, P<0.05)$, whereas it shifted the inactivation curve to a hyperpolarizing voltage at $0.1 \mathrm{mmol} / \mathrm{L}(n=5, P<$ 0.05). (Control: $V_{0.5}=-35.4 \pm 3.3 \mathrm{mV}, k=-14.3 \pm 2.5 ; 0.1 \mathrm{mmol} / \mathrm{L}$ $\mathrm{AlCl}_{3}: V_{0.5}=-41.1 \pm 2.7 \mathrm{mV}, k=-9.2 \pm 2.0 ; 1.0 \mathrm{mmol} / \mathrm{L} \mathrm{AlCl}_{3}: V_{0.5}=$ $-29.8 \pm 6.9 \mathrm{mV}, k=-10.8 \pm 2.4) . \mathrm{AlCl}_{3} 0.1 \mathrm{mmol} / \mathrm{L}$ decreased the inactivation rate constant by $27.3 \% \pm 6.3 \%(n=5, P<0.01)$, whereas $1.0 \mathrm{mmol} / \mathrm{L} \mathrm{AlCl}_{3}$ increased the inactivation rate constant by $44.7 \% \pm 3.4 \%(n=7, P<0.01)$ (Figure 3 ).

Effect of Gin B on $\boldsymbol{I}_{\mathrm{HVA}}$ in hippocampal neurons Gin B at doses of $0.01-20 \mu \mathrm{mol} / \mathrm{L}$ had no effect on $I_{\mathrm{HVA}}$ in normal hippocampal neurons $(P>0.05)$ (Table 1). Gin B inhibited the increase of $I_{\mathrm{HVA}}$ by $\mathrm{AlCl}_{3} 1.0 \mathrm{mmol} / \mathrm{L}$. After a steady increase in the action of $\mathrm{AlCl}_{3}, \mathrm{Gin} \mathrm{B}$ at concentrations of $0.01 \mu \mathrm{mol} / \mathrm{L}$,

Table 1. Effect of Gin B at different concentrations $(0.01,0.1,1.0$, 10 , and $20 \mu \mathrm{mol} / \mathrm{L}$ ) on the amplitude of $I_{\mathrm{HVA}} . n=6 . \quad M e a n \pm \mathrm{SD}$.

\begin{tabular}{lll}
\hline Gin $\mathrm{B} / \mu \mathrm{mol} \cdot \mathrm{L}^{-1}$ & $I_{\mathrm{HVA}} / \mathrm{pA} \cdot \mathrm{pF}^{-1}$ & \\
& Control & Gin B \\
\hline 0.01 & $19.6 \pm 2.9$ & $19.1 \pm 3.9$ \\
0.1 & $19.1 \pm 3.2$ & $19.6 \pm 2.2$ \\
1.0 & $19.4 \pm 1.9$ & $18.8 \pm 1.6$ \\
10 & $20.0 \pm 1.2$ & $18.7 \pm 0.8$ \\
20 & $17.2 \pm 0.9$ & $17.2 \pm 1.3$ \\
\hline
\end{tabular}



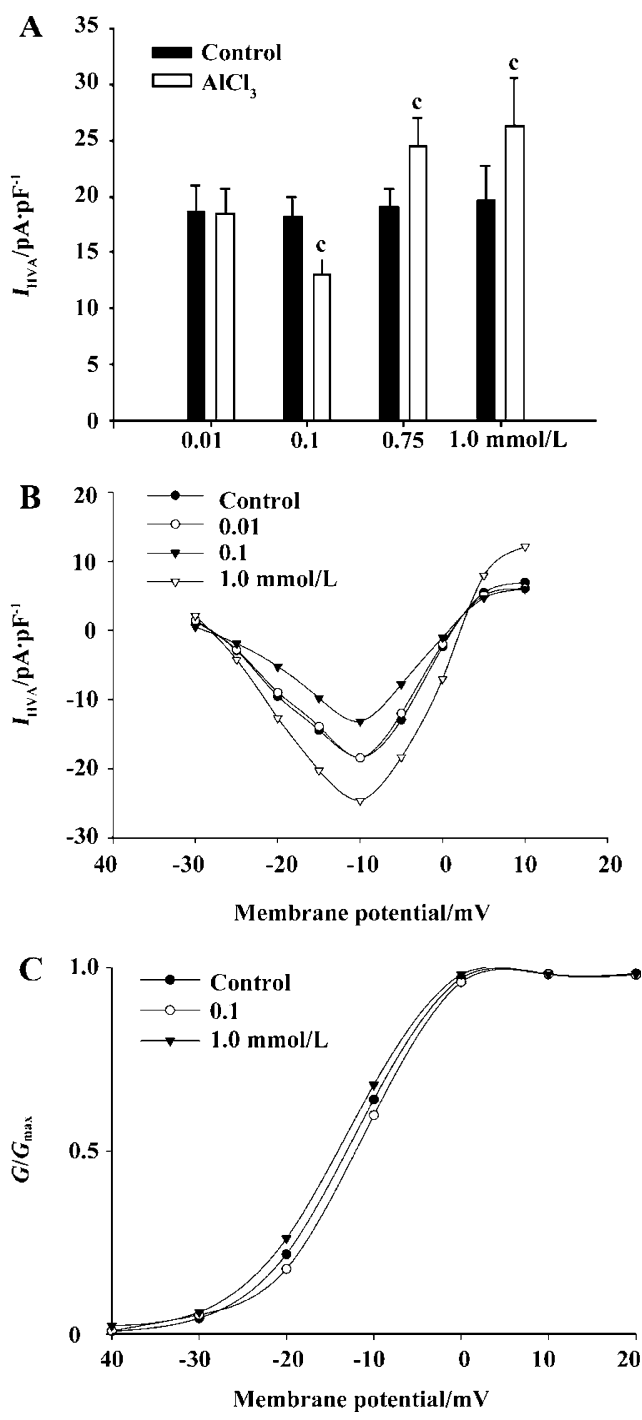

Figure 2. (A) Effect of $\mathrm{Al}$ at different concentrations on the amplitude of $I_{\mathrm{HVA}} .{ }^{\mathrm{c}} P<0.01 v s$ control. (B) Effect of Al at different concentrations on the current-voltage $(I-V)$ relationship of HVA. (C) Effect of $\mathrm{Al}$ at different concentrations on the steady-state conductance $(\mathrm{G})$ and voltage $(\mathrm{V})$ curve. Data were transformed from the $I-$ $V$ data shown in B. $G-V$ parameters were fitted to the Boltzman equation: $G / G_{\max }=1 /\left[1+\exp \left(V_{\mathrm{m}}-V_{1 / 2}\right) / k\right]$, where $G_{\max }$ is the maximum conductance, $V_{1 / 2}$ is the membrane potential at which $50 \%$ of activation was observed, and $k$ is the slop of the function.

$0.1 \mu \mathrm{mol} / \mathrm{L}, 1.0 \mu \mathrm{mol} / \mathrm{L}$, and $10 \mu \mathrm{mol} / \mathrm{L}$ reduced $I_{\mathrm{HVA}}$ by $21.0 \% \pm 4.6 \%(n=7, P<0.05), 57.9 \% \pm 7.8 \%(n=6, P<0.01)$, $79.3 \% \pm 2.7 \%(n=6, P<0.01)$, and $82.4 \% \pm 7.3 \%(n=6, P<0.05)$, respectively. The concentration producing $50 \%$ inhibition by $\mathrm{Gin} \mathrm{B}$ of $\mathrm{Al} 1.0 \mathrm{mmol} / \mathrm{L}$ is $0.0359 \mu \mathrm{mol} / \mathrm{L} \pm 0.0038 \mu \mathrm{mol} / \mathrm{L}$ (Figure 4).

Co-superfusion $\mathrm{AlCl}_{3} 0.1 \mathrm{mmol} / \mathrm{L}$ plus Gin B $10 \mu \mathrm{mol} / \mathrm{L}$ was applied in the same way as $\mathrm{AlCl}_{3} 1.0 \mathrm{mmol} / \mathrm{L}$. For all

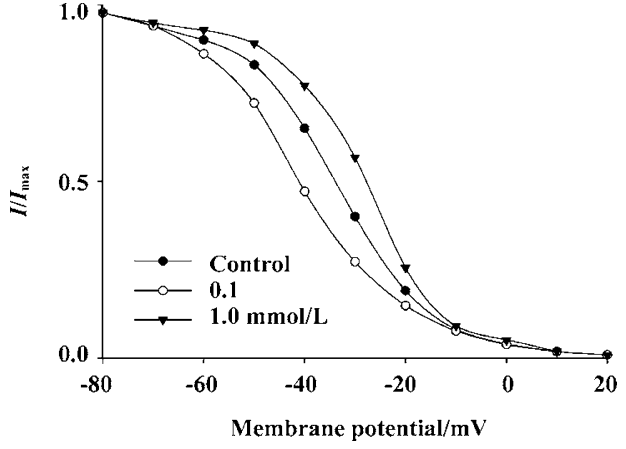

Figure 3. Effects of $\mathrm{Al}$ at different concentrations on the steadystate inactivation curve. $I_{\mathrm{HVA}}$ was measured using a $200 \mathrm{~ms}$ test pulse to $10 \mathrm{mV}$ by $3 \mathrm{~s}$ conditioning prepulse ranging from $-80 \mathrm{mV}$ to +20 $\mathrm{mV}$, with $10 \mathrm{mV}$ increments. Data were fitted to the Boltzman equation: $I / I_{\max }=1 /\left[1+\exp \left(V_{1 / 2}-V_{m}\right) / k\right]$, where $V_{1 / 2}$ is the membrane potential at which $50 \%$ of activation was observed, and $k$ is the slop of the function.

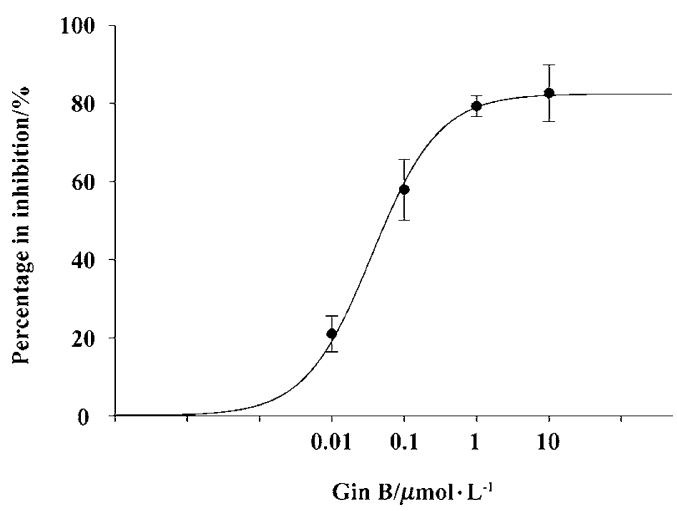

Figure 4. Concentration-response relationship for the inhibition of Gin $\mathrm{B}$ on the action of $\mathrm{AlCl}_{3}(1.0 \mathrm{mmol} / \mathrm{L})$ in hippocampal neurons. In the concentration-response curve for Gin $\mathrm{B}$ each point represents the mean \pm SEM of the percentage inhibition of Gin B from six to seven cells. The curve shown is the fit of the data to the logistic equation $Y=Y_{\max } /\left[1+\left(\mathrm{IC}_{50} / C\right)^{n}\right]$, where $C$ is the concentration of Gin B, $Y$ is the fraction of the maximal inhibition response value, $n$ is the Hill coefficient, and $\mathrm{IC}_{50}$ is the concentration of Gin $\mathrm{B}$ producing $50 \%$ inhibition on the increase in $I_{\mathrm{HVA}}$ by $1.0 \mathrm{mmol} / \mathrm{L} \mathrm{Al}$.

tested neurons ( $n=15)$, there was no change in $I_{\mathrm{HVA}}$ in $53.3 \%$ of the neurons and a slight increase in $I_{\mathrm{HVA}}$ in the remaining neurons $(P>0.05)$. This result indicated that Gin $\mathrm{B}$ had no effect on the action of $\mathrm{Al} 0.1 \mathrm{mmol} / \mathrm{L}$.

Mechanism of action of high concentrations of Al on $\boldsymbol{I}_{\text {HVA }}$ Application of forskolin $10 \mu \mathrm{mol} / \mathrm{L}$ (an agonist of adenylyl cyclase) increased $I_{\mathrm{HVA}}$ by $30.8 \% \pm 7.5 \%(n=14, P<$ $0.05)$. Bath application of forskolin $10 \mu \mathrm{mol} / \mathrm{L}$ in combination with Al $1.0 \mathrm{mmol} / \mathrm{L}$ increased $I_{\mathrm{HVA}}$ by $68.3 \% \pm 8.7 \%(n=31, P<$ 0.05) (Figure 5A). 

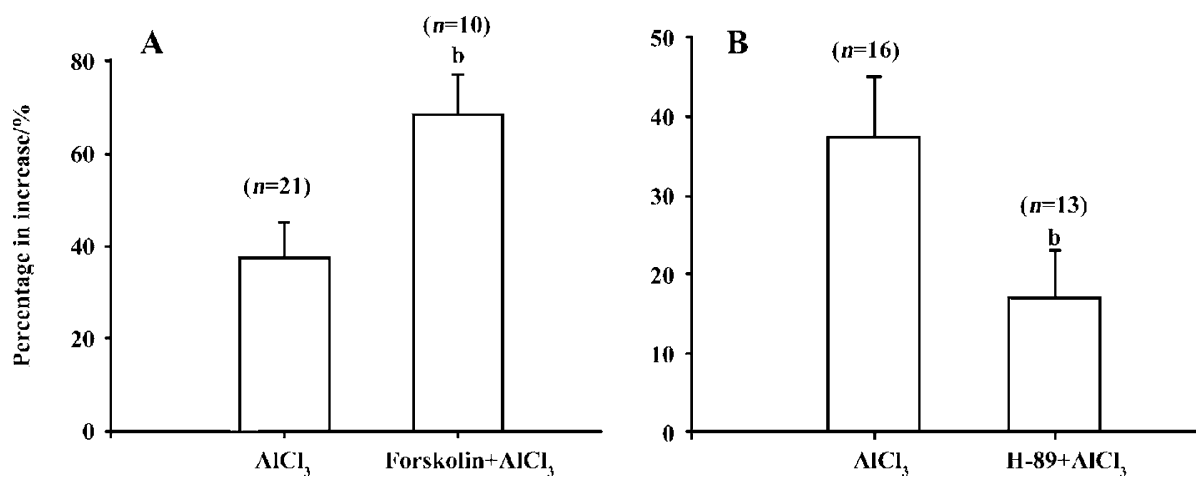

Figure 5. (A) Percentage of increased action by $\mathrm{AlCl}_{3} 1.0 \mathrm{mmol} / \mathrm{L}$ and $\mathrm{AlCl}_{3}$ co-superfusion with forskolin. (B) Percentage of increased action by $\mathrm{AlCl}_{3} 1.0 \mathrm{mmol} / \mathrm{L}$ in the presence and the absence of $\mathrm{H}-89 .{ }^{\mathrm{b}} P<0.05$ vs $\mathrm{AlCl}_{3} 1.0 \mathrm{mmol} / \mathrm{L}$.
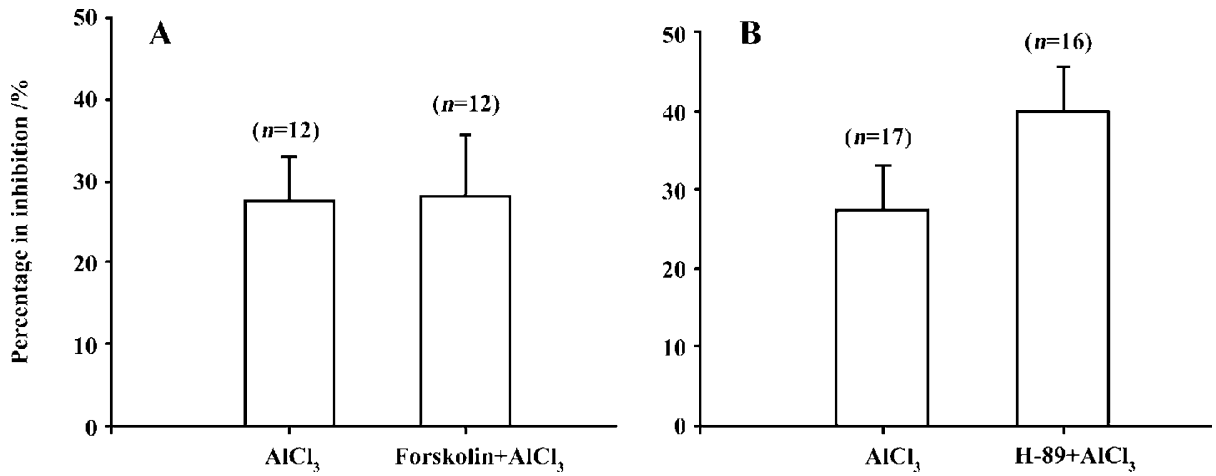

Figure 6. (A) Percentage of inhibitory action by $\mathrm{AlCl}_{3} 0.1 \mathrm{mmol} / \mathrm{L}(27.5 \% \pm 5.6 \%)$ and $\mathrm{AlCl}_{3}$ co-superfusion with forskolin $(28.2 \% \pm$ $7.3 \%)$. (B) Percentage of inhibitory action by $\mathrm{AlCl}_{3} 0.1 \mathrm{mmol} / \mathrm{L}$ in the presence $(39.9 \% \pm 5.7 \%)$ and absence of $\mathrm{H}-89(27.5 \% \pm 5.6 \%)$.

H-89 is a selective antagonist of PKA. In this study, adding $\mathrm{H}-89$ in the pipette solution reduced the amplitude of $I_{\mathrm{HVA}}$ by $42.0 \% \pm 4.1 \%$ (from $20.2 \pm 3.3 \mathrm{pA} \cdot \mathrm{pF}^{-1}$ to $13.9 \pm 3.1 \mathrm{pA} \cdot \mathrm{pF}^{-}$ $\left.{ }^{1}, n=6, P<0.01\right)$ within approximately $80-100 \mathrm{~s} . \mathrm{AlCl}_{3}$ $1.0 \mathrm{mmol} / \mathrm{L}$ was bath applied in the presence of $\mathrm{H}-89$ (10 $\mu \mathrm{mol} / \mathrm{L})$ in the pipette solution. Aluminum increased $I_{\mathrm{HVA}}$ by $17.2 \% \pm 5.8 \%(n=10, P<0.05)$. Compared with the effect of $\mathrm{Al}$ $1.0 \mathrm{mmol} / \mathrm{L}$ on $I_{\mathrm{HVA}}$ without $\mathrm{H}-89(n=29, P<0.05)$, the reduction in $I_{\mathrm{HVA}}$ in the presence of $\mathrm{H}-89$ was significant, indicating that $\mathrm{H}-89$ could, in part, abolish the increase in $I_{\mathrm{HVA}}$ by $\mathrm{Al}$ at high concentrations (Figure 5B).

Mechanism of action of low concentrations of Al on $\boldsymbol{I}_{\text {HVA }}$ To investigate the mechanism by which Al inhibited $I_{\mathrm{HVA}}$ at low concentrations, $\mathrm{AlCl}_{3} 0.1 \mathrm{mmol} / \mathrm{L}$ was applied first and $I_{\mathrm{HVA}}$ was reduced to $12.9 \pm 1.1 \mathrm{pA} \cdot \mathrm{pF}^{-1}$ from $18.5 \pm 1.7$ $\mathrm{pA} \cdot \mathrm{pF}^{-1}(n=12, P<0.01)$. After the current was stable, forskolin $10 \mu \mathrm{mol} / \mathrm{L}$ and $\mathrm{AlCl}_{3} 0.1 \mathrm{mmol} / \mathrm{L}$ were co-applied. Forskolin did not cancel the inhibition of $I_{\mathrm{HVA}}$ by $0.1 \mathrm{mmol} / \mathrm{L}$ $\mathrm{AlCl}_{3}$. The $I_{\mathrm{HVA}}$ after forskolin application was $12.5 \pm 0.9 \mathrm{pA} \cdot \mathrm{pF}^{-1}$ $(n=12, P>0.05)$ (Figure 6A).

In the presence of $\mathrm{H}-89(10 \mu \mathrm{mol} / \mathrm{L}), I_{\mathrm{HVA}}$ was reduced to $13.1 \pm 2.5 \mathrm{pA} \cdot \mathrm{pF}^{-1}$ from $20.1 \pm 4.2 \mathrm{pA} \cdot \mathrm{pF}^{-1}(n=8, P<0.01)$. After the current was stable, $\mathrm{AlCl}_{3} 0.1 \mathrm{mmol} / \mathrm{L}$ was bath applied, and $I_{\mathrm{HVA}}$ was reduced to $12.5 \pm 2.5 \mathrm{pA} \cdot \mathrm{pF}^{-1}$. There was no difference in the percentage inhibition with and without $\mathrm{H}-89$ application $(n=33, P>0.05)$ (Figure 6B).

\section{Discussion}

VDCC in hippocampal neurons are divided into high voltage-dependent channels (HVA) and low voltage-dependent channels (LVA) according to the difference in activation threshold. In the present study we demonstrated that the effect of $\mathrm{Al}$ on $I_{\mathrm{HVA}}$ differed at different concentrations. $\mathrm{Al}$ reduced the amplitude of $I_{\mathrm{HVA}}$ irreversibly at low concentrations $(0.1 \mathrm{mmol} / \mathrm{L})$. This result supports a previous report on dorsal root ganglion (DRG) neurons ${ }^{[7]}$. However, Al inhibited and enhanced $I_{\mathrm{HVA}}$ as $\mathrm{Al}$ concentrations increased 
(between $0.25 \mathrm{mmol} / \mathrm{L}$ and $0.50 \mathrm{mmol} / \mathrm{L}$ ), and the percentage of enhanced $I_{\mathrm{HVA}}$ by $\mathrm{Al}$ in the neurons examined increased with increased $\mathrm{Al}$ concentrations. When $0.75 \mathrm{mmol} / \mathrm{L}$ and $1.0 \mathrm{mmol} / \mathrm{L} \mathrm{Al}$ were bath applied, the amplitude of $I_{\mathrm{HVA}}$ in all neurons tested increased.

The toxic effect of $\mathrm{Al}$ in humans is chronic and accumulative and leads to degradation and apoptosis of cells ${ }^{[14]}$. Acute application of Al inhibits LTP on hippocampal slices of rats as well as in vivo by intracerebroventricular injection. Studies have shown that a series of molecular mechanisms involved in synaptic plasticity, including protein phosphorylation, gene expression, and neurotransmitter release, were regulated by VDCC ${ }^{[15]}$. LTP induced in different areas of the hippocampus has an intimate relationship with $\mathrm{VDCC}{ }^{[16]}$. The inhibition of $I_{\mathrm{HVA}}$ by Al at low concentrations could lead to a reduction in calcium influx, resulting in the reduced release of some neurotransmitters, which might explain impaired LTP in this concentration range. Aluminum increased the amplitude of $I_{\mathrm{HVA}}$ at high concentrations and, thus, led to increased calcium influx, resulting in a series of pathological changes, which could cause impairment of LTP and neuronal damage.

In our study, the actions of $\mathrm{Al}$ on $I_{\mathrm{HVA}}$ differed at different concentrations; thus, it is possible that the mechanism of action is different at different $\mathrm{Al}$ concentrations. Protein phosphorylation modulates the function of VDCC and the AC-cAMP-PKA system plays a key role ${ }^{[17]}$. Thus, forskolin and $\mathrm{H}-89$ were used to investigate whether the action of $\mathrm{Al}$ on $I_{\mathrm{HVA}}$ is involved in this mechanism. H-89 markedly abolished the increase of $I_{\mathrm{HVA}}$ by $\mathrm{Al} 1.0 \mathrm{mmol} / \mathrm{L}$. Co-superfusion with forskolin plus $\mathrm{Al}$ at high concentrations caused more $\mathrm{Ca}^{2+}$ influx. Together these results indicate that an Al-induced increase in $I_{\mathrm{HVA}}$ possibly results from activating cAMPPKA. However, $\mathrm{H}-89$ did not reverse the action of $\mathrm{AlCl}_{3}$ totally, suggesting that other mechanisms must contribute to its action on $I_{\mathrm{HVA}}$ at high concentrations.

Platt ${ }^{[7]}$ reported that the interactions of aluminum with two different binding sites (within and outside) of calcium channels might contribute to the reduction of VDCCs on DRG neurons. Al has been reported to inhibit Mg-dependent enzymes and to interact with phosphorylation sites ${ }^{[18]}$. In the present study, the co-application of forskolin and $\mathrm{Al}$ did not cancel the reduction and the action of $0.1 \mathrm{mmol} / \mathrm{L} \mathrm{Al}$ was not affected by H-89, indicating that the mechanism by which Al reduces $I_{\mathrm{HVA}}$ at low concentrations might not be involved in the cAMP-PKA system. In addition, Gin B effectively canceled the increase of $I_{\mathrm{HVA}}$ by $\mathrm{Al}$ at high concentrations, but had almost no effect on the reduction of $I_{\mathrm{HVA}}$ by $\mathrm{Al}$ at low concentrations, further suggesting that the action of $\mathrm{Al}$ at low concentrations on $I_{\mathrm{HVA}}$ occurs via a different mechanism. The mechanism by which Al reduced $I_{\mathrm{HVA}}$ requires further examination. At intermediate concentration ranges, Al both reduced and enhanced $I_{\mathrm{HVA}}$. The mechanism is not known, but may result from a difference in neurons or from the concentration of $\mathrm{Al}$ itself, which indicated that this concentration might be the point at which $I_{\mathrm{HVA}}$ moves from being inhibited to enhanced and this might be the reason for its complexity and diversity.

$E G$ b is a complex mixture containing $24 \%$ flavonoid glycosides, $6 \%$ terpene lactones, such as ginkgolide A, B, C, $\mathrm{J}$ and bilobalide, a number of organic acids, and various other constituents. Studies have shown that Gin B has many pharmacological effects (ie preventing atherosclerosis, diminishing coagulation of platelets, ameliorating the circulation system) and has a distinctively protective effect on the central nerve and cardiovascular systems. Clinical studies have shown that oral administration of $E G \mathrm{~b}$ in human patients with dementia is effective ${ }^{[19]}$. Gin B can protect cardiocmyocytes and cultured neurons from injury by hypoxia and ischemia through many pathways, for example, by acting as an anti-oxidant ${ }^{[20]}$, acting as the antagonist of plateletactivating factor $^{[21]}$ and by inhibiting NO-stimulated PKC activity $^{[22]}$. Furthermore, Gin B has been shown to prevent neurons from glutamate excitoxicity through a reduction in $\left[\mathrm{Ca}^{2+}\right]_{\mathrm{i}}^{[23]}$ and to have an effect on the glycine-gated chloride channel $^{[24]}$. The present study provides the first evidence that Gin B can cancel the increase of $I_{\mathrm{HVA}}$ by Al, and that Gin B can protect neurons by inhibiting $I_{\mathrm{HVA}}$, providing a possible mechanism for clinical treatment in a number of nervous system diseases. The detailed mechanism by which Gin B inhibits $I_{\mathrm{HVA}}$ remains to be investigated.

\section{References}

1 Tokutake S, Nagase H, Morisaki S, Oyanagi S. Aluminium detected in senile plaques and neurofibrillary tangles is contained in lipofuscin granules with silicon, probably as aluminosilicate. Neurosci Lett 1995; 185: 99-102.

2 Wisniewski HM. Aluminum, tau protein, and Alzheimer's disease. Lancet 1994; 344: 204-5.

3 Gilbert ME, Shafer TJ. In vitro exposure to aluminum does not alter long-term potentiation or glutamate release in rat hippocampal slices. Neurotoxicol Teratol 1996; 18: 175-80.

4 Platt B, Carpenter DO, Busselberg D, Reymann KG, Riedel G. Aluminum impairs hippocampal long-term potentiation in rats in vitro and in vivo. Exp Neurol 1995; 134: 73-86.

5 Zou BD, Xiao HM, Zhang ZD, Li A. Effect of aluminum on evoked potential on hippocampal CA3 area in rats. J Tongji Med Univ 1998; 27: 15-18.

6 Matyja E. Aluminum enhances glutamate-mediated neurotoxicity in organotypic cultures of rat hippocampus. Folia Neuropathol 
2000; 38: 47-53.

7 Platt B, Büsselberg D. Actions of aluminium on voltage-activated calcium channel currents. Cell Mol Neurobiol 1994; 14: 819-29.

8 Trombley, PQ. Selective modulation of $\mathrm{GABA}_{\mathrm{A}}$ receptors by aluminum. J Neurophysiol 1998; 80: 755-61.

9 Platt B, Haas H, Büsselberg D. Aluminum reduces glutamateactivated currents of rat hippocampal neurons. Neuroreport 1994; 5: 2329-32.

10 Zhang ZX, Qi XY, Xu YQ. Effect of ginkgolide B on L-type calcium current and cytosolic $\left[\mathrm{Ca}^{2+}\right]_{\mathrm{i}}$ in guinea pig ischemic ventricular myocytes. Acta Physiol Sin 2003; 55: 24-8.

11 Bastianetto S, Quirion R. EGb 761 is a neuroprotective agent against beta-amyloid toxicity. Cell Mol Biol 2002; 48: 693-7.

$12 \mathrm{Wu}$ XF, Wang QJ, Lou FC. Protective effect of Ginkgolides on rat focal brain ischemia. J China Pharm Univ 2001; 32: 141-5.

$13 \mathrm{Xu} \mathrm{CQ}$, Zhang ZM, Xia ZL, Wu CH, Zhou PA. Acute isolation and identification of CA1 pyramidal neurons in hippocampus of rats. Chin J Appl Physiol 1999; 15: 189-91.

14 Savory J, Herman MM, Ghribi O. Intracellular mechanisms underlying aluminum-induced apoptosis in rabbit brain. J Inorg Biochem 2003; 97: 151-4.

15 Deisseroth K, Heist EK, Tsien RW. Translocation of calmodulin to the nucleus supports CREB phosphorylation in hippocampal neurons. Nature 1998; 392: 198-202.

16 Morgan SL, Teyler TJ. VDCCs and NMDARs underline two forms of LTP in CA1 hippocampus in vivo. J Neurophysiol 1999; 82: 736-40.

17 Kavalali ET, Hwang KS, Plummer MR. cAMP-dependent en- hancement of dihydropyridine-sensitive calcium channel availability in hippocampal neurons. J Neurosci 1997; 17: 5334-48.

18 Macdonald TL, Martin RB. Aluminum ion in biological systems. Trends Biochem Sci 1988; 13: 15-19.

19 Le Bars PL, Katz MM, Berman N, Itil TM, Freedman AM, Schatzberg AF. A placebo-controlled, doubled-blind, randomized trial of an extract of Ginkgo biloba for dementia. J Am Med Assoc 1997; 278: 1327-32.

20 Lenoir M, Pedruzzi E, Rais S, Drieu K, Perianin A. Sensitization of human neutrophil defense activities through activation of platelet-activating factor receptors by ginkgolide B, a bioactive component of the Ginkgo biloba extract EGB 761. Biochem Pharmacol 2002; 63: 1241-9.

21 Bastianetto S, Zheng WH, Quirion R. The Ginkgo biloba extract (EGb 761) protects and rescues hippocampal cells against nitric oxide-induced toxicity: involvement of its flavonoid constituents and protein kinase C. J Neurochem 2000; 74: 226877.

22 Zhu L, Wu J, Liao H, Gao J, Zhao XN, Zhang ZX. Antagonistic effects of extract from leaves of Ginkgo biloba on glutamate neurotoxicity. Acta Pharmacol Sin 1997; 18: 344-7.

23 Kondratskaya EL, Lishko PV, Chatterjee SS, Krishtal OA. BN52021, a platelet activating factor antagonist, is a selective blocker of glycine-gated chloride channel. Neurochem Int 2002; 40: 647-53.

24 Chatterjee SS, Kondratskaya EL, Krishtal OA. Structureactivity studies with Ginkgo biloba extract constituents as receptor-gated chloride channel blockers and modulators. Pharmacopsychiatry 2003; 36: S68-77. 